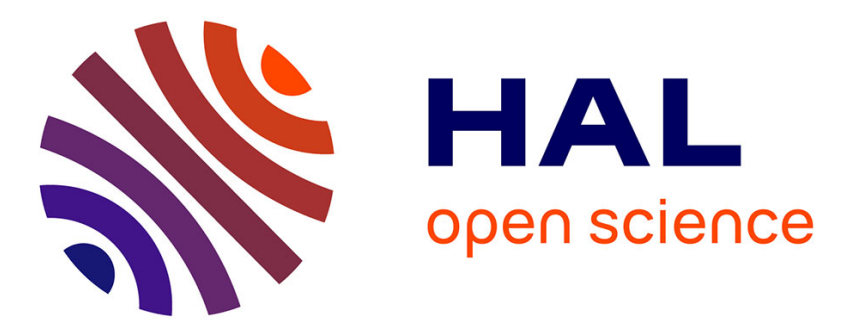

\title{
Applications of the Factory Design and Improvement Reference Activity Model
}

Sangsu Choi, Gyhun Kang, Kiwook Jung, Boonserm Kulvatunyou, Kc Morris

\section{To cite this version:}

Sangsu Choi, Gyhun Kang, Kiwook Jung, Boonserm Kulvatunyou, Kc Morris. Applications of the Factory Design and Improvement Reference Activity Model. IFIP International Conference on Advances in Production Management Systems (APMS), Sep 2016, Iguassu Falls, Brazil. pp.697-704, 10.1007/978-3-319-51133-7_82. hal-01615741

\section{HAL Id: hal-01615741 \\ https://hal.inria.fr/hal-01615741}

Submitted on 12 Oct 2017

HAL is a multi-disciplinary open access archive for the deposit and dissemination of scientific research documents, whether they are published or not. The documents may come from teaching and research institutions in France or abroad, or from public or private research centers.
L'archive ouverte pluridisciplinaire $\mathbf{H A L}$, est destinée au dépôt et à la diffusion de documents scientifiques de niveau recherche, publiés ou non, émanant des établissements d'enseignement et de recherche français ou étrangers, des laboratoires publics ou privés. 


\title{
Applications of the Factory Design and Improvement Reference Activity Model
}

\author{
SangSu Choi ${ }^{1}$, Gyhun Kang ${ }^{1}$, Kiwook Jung ${ }^{2}$, Boonserm Kulvatunyou ${ }^{2}$, and KC \\ Morris $^{2}$ \\ 1 IGI, Clarksburg, USA \\ \{sangsu.choi,gyhun.kang\}@igiamerica.com \\ 2 National Institute of Standards and Technology, Gaithersburg, USA \\ \{kiwook. jung, boonserm. kulvatunyou, kcm\}@nist.gov
}

\begin{abstract}
Developed countries and global manufacturing enterprises are leading the way for developing smart manufacturing systems (SMS) to improve competitiveness and possibly make technological breakthroughs. SMS is based upon the integration of information and communication technology with manufacturing technology; and all the heterogeneous technologies must be seamlessly connected. However, there is a lack of guidance in what technologies should be deployed and how they may be used. This paper introduces a reference activity model and describes various ways in which it can be used as guidance for deploying smart manufacturing technology.
\end{abstract}

Keywords: Smart manufacturing systems design and analysis. Cyber-physical systems. Factory design and improvement. Manufacturing enterprise integration

\section{Introduction}

The world is now going through another industrial revolution where manufacturing enterprises will reach a new level of interconnectivity both within their production environments and throughout their business value chains. Examples of work towards this vision are seen world-wide including Industry 4.0 in Germany, Industrial Internet Consortium in the United States, Robot Strategy in Japan, and Manufacturing 2025 in China [2]. The core of the current industrial revolution is the development of smart manufacturing systems (SMS). SMS emphasize the integration of core technologies, such as, sensors, cyber-physical systems (CPS) [1], additive manufacturing, sustainable manufacturing, Information and Communication Technologies (ICT), cloud computing, big data, hologram, and cyber security with infrastructure components (such as, standards, regulations, organizations, and trainings) [2]. This paper introduces a Factory Design and Improvement (FDI) model as a reference activity model and describes how it can be used as a guide to develop a SMS. The activity model provides a high-level view that helps to integrate the core technologies of SMS with components in a manufacturing enterprise. 


\section{Smart Manufacturing Systems}

Figure 1 shows a SMS concept [3] where all manufacturing enterprise functions including materials management, productions, logistics, services, and products are connected on a network as a unified system and the production is controlled through a CPS. A CPS consists of virtual factory models that are connected with the real world and are continually exchanging information with enterprise software through distributed software services (a.k.a. the Internet of Services or IoS) and with distributed devices and equipment (a.k.a. the Internet of Things or IoT or more specifically Industrial Internet of Things - IIoT). Analyses from the CPS can produce dynamic plans for optimally controlling the entire production process.

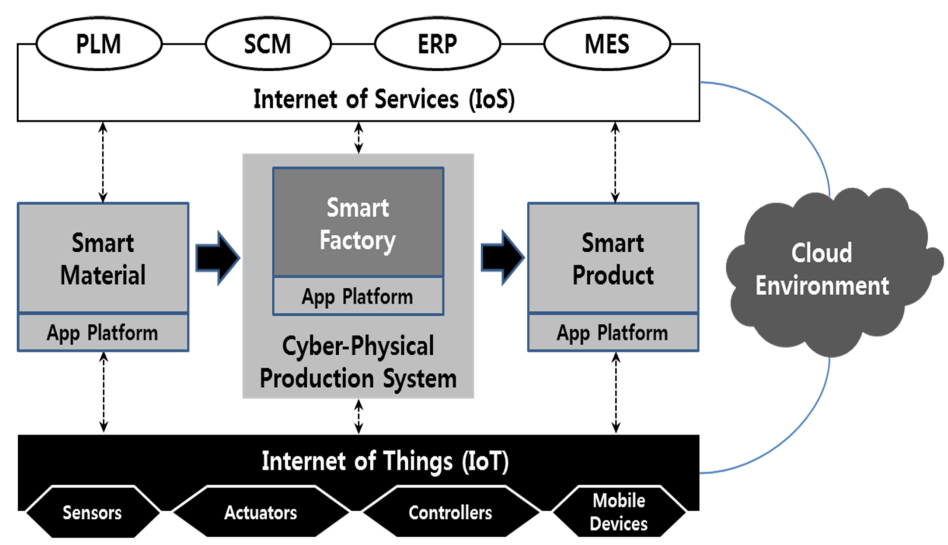

Fig. 1. The concept of SMS (Source: [3])

Standards are important to enable such a CPS-based SMS [4,5] and new standards are needed to connect various IoT and IoS technologies. In the IoT sector, ISO/IEC 30141 [6] was proposed by China to define a reference structure for IoT. IEEE 802.24 [7] is also a representative standard activity. The 'IEC SG8 Industry 4.0 - Smart Manufacturing' [8] strategic group, comprised of members mainly from Europe and United States, is working on IEEE P2413 - Standard for an Architectural Framework for the Internet of Things (IoT). The group is leading the way for the first international standard for an IoT architectural framework. OneM2M [9] was established to improve Machineto-Machine (M2M) communication standards that are inconsistent globally due to variances in different regions. In the IoS sector, standards are being enhanced based on representative functional systems under use in manufacturing enterprises. The maturity of standards in this sector are relatively high. For product life-cycle management (PLM), STEP 242 [10] is the representative standard, while for supply chain management (SCM) and enterprise resource planning (ERP), OAGIS [11] is used as a standard. For MES, ISA-95 [12] are used. On the other hand, IEC 62264 Enterprise-Control Integration [13] is used for integration across these functional systems. 


\section{Factory Design and Improvement Model}

FDI, developed by the National Institute of Standards and Technology (NIST), formalizes activities, enterprise software functions, and information relevant to operation design and management tasks in a SMS, such as that shown in Figure 1. FDI is based upon the work processes $[14,15]$ common to global manufacturing enterprises in the areas of factory, manufacturing line, process, and equipment operations. It currently consists of four activities and twenty-eight tasks. The top-level activities are illustrated in Figure 2. Details of the FDI can be found in [16].

FDI is modelled using IDEF0, where tasks are represented and related via Inputs (data), Outputs (products and performance measures), Controls (organization), and Mechanisms (tools/systems), collectively called ICOMs as is shown in Figure 2. Information inter-connectivity between tasks is expressed through these ICOMs. FDI tasks encompass both factory design and improvement tasks. Factors related to both cyber and physical systems of a SMS can be reflected in this model. FDI encompasses all control levels as described in the ISA-88 reference control architecture [17] from the equipment level up to the enterprise level. Thus, the FDI model is suitable for identifying information requirements for standard-based integration between software tools across control levels [18].

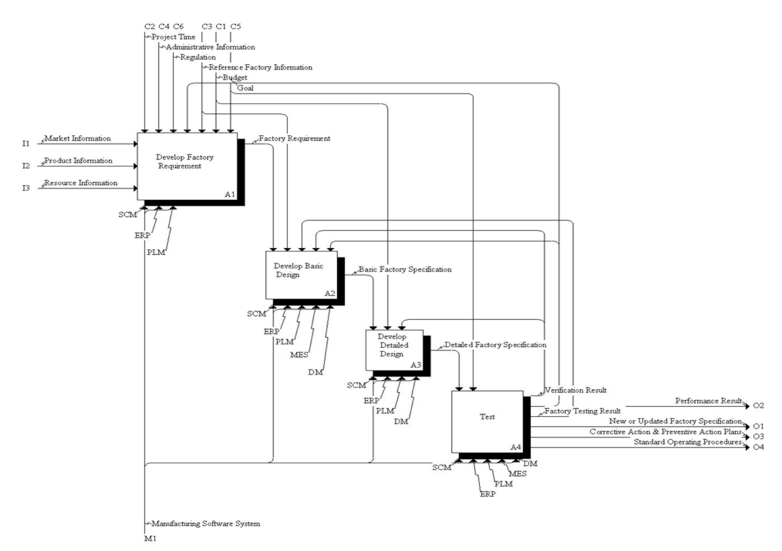

Fig. 2. IDEF0 model of the 'Develop/Update a Factory' activity (Source: [16])

\section{Applications of FDI}

FDI can be used in different ways to facilitate the deployment of smart manufacturing technologies. This section introduces three uses for the FDI model—as a

- Guideline for planning for new factory designs and improvements to existing factories 
- Tool for assessing current capabilities of a manufacturing enterprise in terms of digital information flows for operations planning

- Basis for guiding the development of interoperability and integration technology within the operational environment.

\subsection{Work Guideline}

As previously mentioned, the FDI model provides an overview of the operational processes in a global manufacturing enterprise involving the factory, manufacturing line, manufacturing processes, and equipment. The model can be used to guide the analysis of performance measures, organizations, tools, systems and related data. As such, the FDI model can be used as a work guideline when designing or operating factories. For example, the FDI model breaks down the design activity into basic and detailed design tasks. A factory development project following this break down resulted in a better delivery time because plant engineering and construction could start earlier without having to wait for all the design details to be completed $[14,19]$. The FDI model can also be used when adopting systems and tools to a specific workplace. A case of work guideline is described in Table 1.

Table 1. A case: 'verify process throughput'

\begin{tabular}{|c|c|l|}
\hline ICOM & Factors & \multicolumn{1}{c|}{ Description } \\
\hline \multirow{2}{*}{ INPUT } & Information & $\begin{array}{l}\text { Product Info. Production schedule, Equipment } \\
\text { Info., Labor Info. }\end{array}$ \\
\hline OUTPUT & Performance Indexes & Lead time, cycle time, WIP, Production output \\
\hline \multirow{3}{*}{ CONTORL } & Work process & PLM-based work process \\
\cline { 2 - 3 } & Methodology & DMAIC, PDCA \\
\cline { 2 - 3 } & People & Process designer, Process manager \\
\hline \multirow{2}{*}{ MECHANISM } & Tools / System functions & $\begin{array}{l}\text { Stochastic method, Discrete event simulation } \\
\text { E-BOM, M-BOM management in PLM } \\
\text { Production planning in ERP }\end{array}$ \\
\hline
\end{tabular}

\subsection{SMS Assessment}

The ICOMs identified in FDI enable assessment of SMS readiness levels (SMSRL).

SMSRL evaluate a factory in four dimensions: organization, ICT, performance management, and information connectivity as shown in Figure 3. Consolidating these four dimensions into a single measure creates a maturity index reflecting a manufacturer's readiness to deploy smart manufacturing solutions or to participate in a network of smart manufacturers.

The output of the SMSRL model can be used in two different ways. The first is to identify and prioritize which smart manufacturing initiatives a manufacturer should undertake to have the greatest impact on operational performance. For example, based 


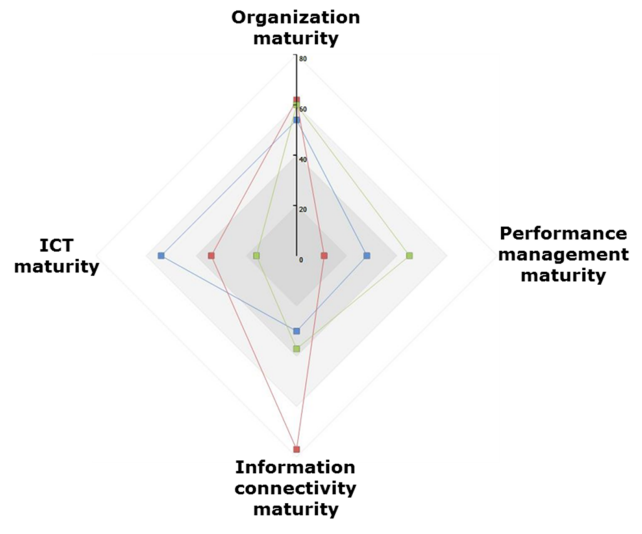

Fig. 3. SMSRL' four categories

on a classification study Table 2 shows the recommendation for the area of improvement focus given the SMSRL value. The second use of the output is to provide criteria for selecting a supplier to be included in a supply chain. When designing and assembling a supply chain, understanding each supplier's smart manufacturing readiness level can better inform sourcing decisions, resulting in overall improved performance.

Table 2. High-level recommendation

\begin{tabular}{|c|c|c|}
\hline SMSRL Range & Performance Category & Improvement Focus \\
\hline \multirow{2}{*}{$0-0.33$} & Financial & IT \\
\cline { 2 - 3 } & Operational & Information Connectivity \\
\hline \multirow{2}{*}{$0.33-0.78$} & Financial & Organization \\
\cline { 2 - 3 } & Operational & Inconclusive \\
\hline \multirow{2}{*}{$0.78-1$} & Financial & IT \\
\cline { 2 - 3 } & Operational & Information Connectivity \\
\hline
\end{tabular}

\subsection{Data Interoperability and Integration for SMS}

Schemas for enabling information interoperability between the FDI-defined tasks are under development. These schemas take into account not only the FDI tasks and data, but also relevant performance indicators and information connectivity. Based on these schemas, cases have been published where various heterogeneous software were seamlessly integrated in a SMS's cyber system [20].

As shown in Figure 4, the schemas consist of four major components related to product, process, resource, and plant data. The product data component represents information about the products and components produced by a plant. The resource data component represents information about the manufacturing equipment, manpower, and 
material handling system(s) (MHS). The process data component represents information on each process and the relationship between processes. The plant data component represents factory operation information and information on the factory's construction, such as the relations among the products, processes, and resources, and the facility configuration and master plan. The schemas are being refined to expand the scope of factory's physical and cyber systems connectivity.

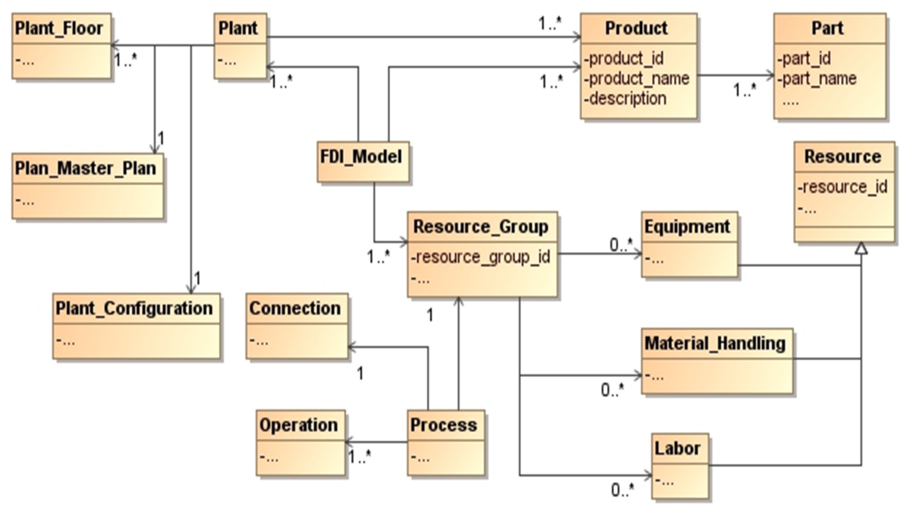

Fig. 4. Conceptual model of the interoperable schema

The adoption of the FDI as a work guide line (as described in 4.1) along with the deployment of the integrated system based on the illustrated schema resulted in significant reductions in times required for a new factory development/improvement projects as well as operational performance improvements. In particular, the deployment in the electromechanical component factory resulted in the reduction in the combined time to complete critical project activities, which included layout design, capacity analysis and material flow analysis, from 6 weeks to 1.5 weeks in the new factory development case and from 4 weeks to 1 week in the factory improvement case [14]. A breakdown of how these improvements affected factory performance is summarized in Table 3.

Table 3. Effectiveness of FDI Application to Factory Performance (Source: [14,20])

\begin{tabular}{|c|c|c|c|}
\hline & \multicolumn{3}{|c|}{ Improvement of factory performance } \\
\hline & Cost index & Productivity index & Capacity index \\
\hline New factory development & $25 \%$ & $25 \%$ & $12 \%$ \\
\hline Existing factory improvement & $20 \%$ & $20 \%$ & $9.20 \%$ \\
\hline & \multicolumn{3}{|c|}{ Reduction in project time } \\
\hline & Layout design & Material flow analysis & Capacity analysis \\
\hline New factory development & $55 \%$ & $50 \%$ & $35 \%$ \\
\hline Existing factory improvement & $40 \%$ & $45 \%$ & - \\
\hline
\end{tabular}




\section{Conclusions}

This paper introduced FDI as reference activity model for enabling a SMS. Three applications of the FDI were described including as a work guideline, as a basis for maturity assessment of SMS, and as a specification for information requirements of a CPS-based SMS integration schema. While FDI tasks were designed as an abstract representation of the work involved in factory design and improvement, they may be further decomposed to reflect the more specific tasks within a particular factory. Validation of this approach is ongoing. The model is also being improved based on the development of the SMS maturity assessment by considering other assessment models, such as, MESA Manufacturing Operation Management Maturity Model [21] and the Supply Chain Readiness Level [22]. Currently, a Web system to enable the SMSRL self-assessment is under development. Also, research on artificial intelligence (AI) is being conducted in order to extract the optimized recommendations from the model.

Disclaimer: Any mention of commercial products is for information only; it does not imply recommendation or endorsement by NIST.

\section{References}

1. Lee, J., Bagheri, B., Kao, H.A.: A Cyber-physical Systems Architecture for Industry 4.0based Manufacturing Systems. Manufacturing Letters 3, 18-23 (2015)

2. Kang, H.S., Lee, J.Y., Choi, S., Kim, H., Park, J.H., Son, J.Y., Kim, B.H., Do Noh, S.: Smart Manufacturing: Past Research, Present Findings, and Future Directions. International Journal of Precision Engineering and Manufacturing-Green Technology 3(1), 111-128 (2016)

3. LG CNS: http://www. lgcnsblog.com

4. Kibira, D., Choi, S.S., Jung, K., Bardhan, T.: Analysis of Standards Towards SimulationBased Integrated Production Planning. In: Umeda, S., Nakano, M., Mizuyama, H., Hibino, H., Kiritsis, D., Cieminski, G.v. (eds.) Advances in Production Management Systems: Innovative Production Management Towards Sustainable Growth, vol. 460, pp. 39-48. Springer International Publishing (2015)

5. Lu, Y., Morris, K., Frechette, S.: Current Standards Landscape for Smart Manufacturing Systems. Tech. rep., National Institute of Standards and Technology (2016)

6. ISO/IEC CD 30141: http://www.iso.org/iso/home/store/catalogue_tc/ catalogue_detail.htm?csnumber $=65695$

7. IEEE: http://www . ieee802.org/24/

8. IEC SG8: http://www.iec.ch/dyn/www/

9. Coskun, H., Pfeifer, T., Elmangosh, A., Al-Hezmi, A.: Open M2M data-Position Paper. In: IEEE 38th Conference on Local Computer Networks Workshops. pp. 904-911. IEEE (2013)

10. Feeney, A.B., Frechette, S.P., Srinivasan, V.: A Portrait of an ISO STEP Tolerancing Standard as an Enabler of Smart Manufacturing Systems. Journal of Computing and Information Science in Engineering 15(2), 021001 (2015)

11. Open Applications Group: http://www . oagi .org/dnn2/

12. International Society of Automation: https://www.isa.org/isa95/

13. ISO/IEC 62264-1:2013: http://wWw.iso.org/iso/catalogue_detail.htm? csnumber $=57308$

14. Choi, S., Lee, B., Shin, Y., Park, Y., Kang, H., Jun, C., Jung, J., Noh, S.: The Integrated Design and Analysis of Manufacturing Line (I)-Digital Virtual Manufacturing Based on Automated Modeling \& Simulation System. Trans. Soc. CAD/CAM Eng 19(2), 138-147 (2014) 
15. Choi, S., Lee, B., Shin, Y., Park, Y., Kang, H., Jun, C., Jung, J., Noh, S.: The Integrated Design and Analysis of Manufacturing Line (I)-Digital Virtual Manufacturing Based on Automated Modeling \& Simulation System. Trans. Soc. CAD/CAM Eng 19(2), 148-156 (2014)

16. Jung, K.: An Activity Model for Smart Factory Design and Improvement. Production Planning \& Control (2016)

17. Instrument Society of America: Batch control. Part 1, Part 1,. ISA, Research Triangle Park, N.C. (1995), oCLC: 36500861

18. Choi, S., Jung, K., Kulvatunyou, B., Morris, K.: An Analysis of Technologies and Standards for Designing Smart Manufacturing Systems. Trans. Soc. CAD/CAM Eng 16(6), 1107-1115 (2015)

19. Choi, S., Kim, B.H., Do Noh, S.: A Diagnosis and Evaluation Method for Strategic Planning and Systematic Design of a Virtual Factory in Smart Manufacturing Systems. International Journal of Precision Engineering and Manufacturing 16(6), 1107-1115 (2015)

20. Choi, S., Jun, C., Zhao, W.B., Noh, S.D.: Digital Manufacturing in Smart Manufacturing Systems: Contribution, Barriers, and Future Directions. In: Umeda, S., Nakano, M., Mizuyama, H., Hibino, H., Kiritsis, D., Cieminski, G.v. (eds.) Advances in Production Management Systems: Innovative Production Management Towards Sustainable Growth, pp. 21-29. No. 460 in IFIP Advances in Information and Communication Technology, Springer International Publishing (2015)

21. MESA International: https://services.mesa.org/ResourceLibrary/ ShowResource/a4fcb3cc-bc28-4f87-84cb-3da7432cc3b2

22. Tucker, B., Paxton, J.: SCRL-model for Human Space Flight Operations Enterprise Supply Chain. In: Aerospace Conference. pp. 1-9. IEEE (2010) 